\title{
Promoting Intrinsic and Extrinsic Motivation among Chemistry Students using Computer-Assisted Instruction
}

\author{
Isiaka A. Gambari \\ Federal University of Technology, Nigeria \\ Bimpe E. Gbodi \\ IBB University, Nigeria \\ Eyitao U. Olakanmi \\ University of Johannesburg, South Africa \\ Eneojo N. Abalaka \\ Federal University of Technology, Nigeria
}

\begin{abstract}
The role of computer-assisted instruction in promoting intrinsic and extrinsic motivation among Nigerian secondary school chemistry students was investigated in this study. The study employed two modes of computer-assisted instruction (computer simulation instruction and computer tutorial instructional packages) and two levels of gender (male and female) using pretest-posttest experimental group design. Ninety (45 males and 45 females) senior secondary one (SS1) students from three secondary schools in Minna, Nigeria, made up the sample. The schools were purposively sampled and randomly assigned to experimental and control groups. The Experimental Group I was taught two selected concepts of chemistry using computer simulation instructional package (CSIP), Experimental Group II was exposed to computer tutorial Instructional package (CTIP) while conventional teaching method (CTM) was used for the Control Group. Validated Chemistry Achievement Test (CAT) and Chemistry Motivation Questionnaire (CMQ) with reliability coefficient of 0.89 and 0.94 respectively were used for data collection. Classroom observations as well as interview schedules were also conducted. Data from CAT and CTM were analyzed using One-way ANOVA and Scheffe's posthoc test, while the data from the classroom observations and interview schedules were thematically analyzed. The outcome of this study revealed that students taught with CSIP performed better than those in CTIP and CTM groups. The CSIP and CTIP were found also to be gender friendly. Moreover, students taught with CSIP had higher intrinsic and extrinsic motivation than their counterparts in CTIP and CTM respectively. Based on the findings, it was recommended that chemistry teachers should employ computer simulation for improving their students' performance and motivation in the subject.
\end{abstract}

Keywords: Computer-assisted instruction; Tutorial; Simulation; Gender; Intrinsic motivation; Extrinsic motivation 


\section{Introduction}

The secret of technological development of any nation lies in the study of science. Unfortunately, the study of science in Nigeria has been impeded by a lot of bottlenecks right from primary school through secondary to tertiary level of education (James, 2001). The importance of chemistry in science and technology cannot be overemphasized. Chemistry is often called 'the central science', because its interests lie between those of physics and biology. Nigerian government having realized the importance of chemistry in the field of science and technology made it one of the core-courses to be offered by science oriented students (FRN, 2009). In the last decade, reports have shown that secondary school students' performance in chemistry on national examinations in Nigeria has been very poor as revealed in Table 1.

Table 1. Percentage Performance of Students in May/June WASSCE, 2005-2011 in Nigeria at Credit Level and Above

\begin{tabular}{ccccc}
\hline Year & Biology & Chemistry & Mathematics & Physics \\
\hline 2005 & 35.74 & 50.94 & 38.20 & 41.53 \\
2006 & 49.23 & 44.90 & 41.12 & 58.02 \\
2007 & 33.37 & 45.96 & 46.75 & 43.19 \\
2008 & 33.94 & 44.44 & 57.27 & 48.26 \\
2009 & 28.58 & 43.69 & 47.04 & 47.83 \\
2010 & 50.70 & 49.65 & 41.16 & 20.98 \\
2011 & 37.80 & 48.68 & 31.88 & 62.84 \\
\hline
\end{tabular}

Source: WAEC.

From research evidences, educators see the pressing need to reconsider the techniques and methods of instruction. To address these challenges and issues, there is the need for instructional system and support technology to give consideration to meaningful learning in basic science.

According to Olorukooba (2007) and Jegede (2007), students consider chemistry to be a difficult field of study. Students' inability to comprehend and remember what has been learned is mostly caused by the teacher-centered approach that makes learners passive listeners. The persistent use of traditional teaching method where chemistry teachers transmit knowledge to the students who most of the times are inactive in the classroom has not been promoting effective learning. Lack of motivation has been identified as one of the causes of poor performance in science. Glynn, Taasoobshirazi, and Brickman (2009) and Glynn, Taasoobshirazi, and Brickman (2007) concluded that motivation to learn science positively related to college science performance.

Balancing of equation and periodicity constitute parts of chemistry concepts that teachers find difficult to teach their students, and students also find it difficult to understand (WAEC, 2012). Science courses require students to recall many facts and then connect old and new concepts. Students often rely on surface strategies for memorizing facts (Gambari, 2004; Zeegers, 2001) without any focus on content comprehension or connection. This poses a problem for college science teaching, because, if meaningful learning does not occur, students may not truly understand the material and ultimately make necessary connections for solving problems (Cavallo, 
Potter, \& Rozman, 2004). The absence of meaningful learning may be due to the manner in which material is presented or to the lack of awareness of actual skills needed to reach meaningful learning levels (Gambari, 2010).

Traditional instructional methods have given insufficient opportunities for student to construct their own learning. Eliciting students' individual capabilities, intelligence and creative thinking can only be achieved through student centered instructional methods (Adegoke, 2011). Large enrollment in science courses, make it difficult to address the specific needs of individuals. Anecdotal evidence suggests that many of these students are poorly motivated, do not see the relevance of science to their careers, and find science frustratingly difficult (Arwood, 2004; Cavallo et al., 2004; Emeke \& Adegoke, 2001). Poor motivation in science often leads to low achievement (Glynn et al., 2007). In order for students to be motivated to learn in any discipline, they must participate in activities that are personally meaningful and worthwhile (Glynn \& Koballa, 2006).

Computer-Assisted Instruction (CAI) software could be used to transform classroom instruction into a series of rich memorable experiences and therefore reduce boredom and forgetfulness (Achuonye, 2011; Yusuf \& Afolabi, 2010). It can also solve the problem of lack of instructional material for teaching chemistry, it can be used to change students' perspective that chemical concepts are abstract and difficult to understand. Computer supported learning environments offer several facilities that can be used to improve the teaching and learning of chemical processes. Computer enables repeated trials of an experiment with considerable ease in limited time. It also provides immediate/constant feedback, allows simultaneous observation of graphical representations, and offers a flexible environment that enables students to proceed on their own pace (Gambari, 2004; Kara \& Yesilyurt, 2007). Major classifications of CAI lessons include tutorials, drill and practice, simulations, and instructional games (Badmus, 2007). Each basic design provides a unique method for using the computer to teach, reinforce, practice, or apply information.

Using interactive learning environment such as computer simulations and tutorial instruction to teach abstract topics enables students to become active learners. It also provides opportunities for students to construct and understand difficult concepts more easily (Gambari, Yaki, Gana \& Ughovwa, 2014). In this context, appropriate simulations and applications based on simulations generally increase learning speed by allowing students to express their real reactions easily (Tuysuz, 2010). According to Burns and Myhill (2004), complex information given to the students is simplified by technology and provides them opportunities to learn by doing. Computer simulations can help reduce the costs associated with the chemicals and equipment necessary for laboratory experiments. They can also save time in situations in which there are few variables being examined. It is considered that, if used adequately, simulations would make it easy to control variables and may even prevent traditional classroom management problems (Gambari, Falode, Fagbemi, \& Idris, 2013). Integrating computer simulations into teaching and learning helps students integrate separate facts, concepts, and principles into functional units and assimilate them with other units; they are used in situations in which several knowledge elements have been learned independently and must be applied collectively (Efe \& Efe, 2011).

Previous research has demonstrated the effectiveness of computer simulations on student learning. Studies suggest that well-designed computer simulations have positive effects on 
learning, creativity, decision-making, communication, thinking power and initiatives (Akpan \& Andre, 2000; Saminathan, 2012; Winberg \& Headman, 2007). A good number of these studies focused on the acquisition of specific content knowledge. For example, Akpan and Andre (2000) found that students who used a computer simulated frog dissection learned significantly more on anatomy course than those who performed actual dissections. Trey and Khan's (2008) investigation indicated that dynamic computer-based analogies may enhance college students' learning of unobservable phenomena in chemistry. Winberg and Headman (2007) developed a computer simulated pre-lab, which aimed to prepare students cognitively to real laboratory activity about acid-base titration. As a result of their study, they concluded that the experimental group showed a positive attitude towards learning. Saminathan (2012) found computer-based instruction to be an effective method than the traditional method of teaching chemistry.

Other investigations reported less impressive results in utilizing computer simulations in science instruction. Some of them have found no advantage to using simulations over traditional methods. For example, Winn, Walker, Greene, and Mansell (2006) compared college undergraduate's achievement of oceanography concepts through field and simulated experiences. Results indicated that there was no difference in overall learning between the fieldwork and simulation groups. However, other investigations have shown the use of computer simulations to be less effective than traditional instruction and hands-on laboratory approaches (Michael, 2001; Rieber, 1990).

In computer tutorial, information is taught, verified, and reinforced through interaction with the computer. Tutorials are often categorized as linear and branching tutorials (Egunjobi, 2004). A simple, linear tutorial gives the same instructional sequence of explanation, practice, and feedback to all learners regardless of differences in their performance. A more sophisticated, branching tutorial directs learners along alternate paths depending on how they respond to questions and whether or not they show mastery of certain parts of the material. Even branching tutorials can range in complexity by the amount of branching they allow and how fully they diagnose the kinds of instruction that a student needs (Doering \& Veletsianos, 2009). Students are typically questioned during the tutorial to verify comprehension. Tutorials should teach well-defined objectives thoroughly enough to eliminate the need for repetition through another teaching system (Kara \& Yesilyurt, 2007).

Literature evidence in Yaakub and Finch (2001), Egunjobi (2004), and Badmus (2007) revealed the effectiveness of computer tutorial mode over the traditional method in classroom setting across different disciplines at secondary schools level both in Nigeria and outside Nigeria. For instance, Kara and Yesilyurt (2007) assessed the effects of tutorial and edutainment software programs on students' achievements, misconceptions and attitude towards biology. After the treatment, tutorial and edutainment improved students' performance and changed students' attitudes towards biology. Similarly, Egunjobi (2004) reported that students taught some concepts in geography using computer tutorial mode performed better than those in computer game and computer drill and practice instructional groups respectively. Akram, Athar, and Ali (2011), reported the effectiveness of computer tutorial on the chemistry students' achievement over traditional method at higher level. However, other studies such as Ramanchandram and Scottler (2003) found no significant difference between the traditional method and tutorial mode on 
achievement. Most of these studies were based on the regularly used tutorial mode which incorporated text-only strategy and did not utilize pictures and audio.

Gender has been identified as one of the factors influencing students' performance at Senior Secondary School level in Nigeria (Anagbogu \& Ezeliora, 2007). Different results and views of researchers as in studies of various subjects such as science, arts, and vocational education in developing countries show that female and male students perform differently as a result of cultural and traditional reasons (Wasagu \& Muhammad 2007). Although some researchers (Adesoji \& Babatunde, 2005; Fagbemi, Gambari, Gbodi, \& Oyedum, 2011; Gambari, 2004) found that male and female students performed equally well in chemistry, biology, physics, and social studies) using computer-based instructional packages. Therefore, it is not clear how gender will influence learning when the different strategies of the simulation and tutorial modes are used in teaching chemistry; hence, the inclusion of gender in this study became necessary.

Motivation is one of the states that drives and sustains learning behaviors. There are many motivational constructs that could relate to academic success in college science. However, researchers have identified intrinsic and extrinsic motivation, goal orientation, task value, selfdetermination, self-efficacy, and assessment anxiety as important constructs for science learning (Glynn \& Koballa, 2006; Glynn et al., 2009). However, the present study focused on intrinsic and extrinsic motivation as predicator of success in chemistry.

Intrinsic motivation refers to internal desires to perform a particular task which is rewarded by completing the task itself, whereas extrinsic motivation refers to performance of a task in order to receive an external reward (Ryan \& Deci, 2000). In academic situations, intrinsic motivation leads to deeper processing, greater mastery, and better implementation of learning strategies (Covington, 2000). Intrinsically motivated students are also more likely to persist with challenging tasks and other positive classroom behaviors as well as perform better academically than extrinsically motivated students who might have to been bribed before they perform the given tasks (Ryan \& Deci, 2000; Walker, Greene, \& Mansell, 2006).

Extrinsic motivation generally drives behaviors when students complete tasks for an external outcome. Extrinsically motivated students who fall closer to active personal commitment on the continuum may be driven to act primarily because of the reward. However, these rewards may also have some intrinsic elements, for instance, receiving an ' $A$ ' makes the student feel good (Walker et al., 2006).

Motivation to learn science at the Junior Secondary School level (Middle School) is one of the most important predictors of science course success (Britner \& Pajares, 2006). Moos (2010) reported that participants who had high extrinsic and high intrinsic motivation used significantly more planning and monitoring processes when compared to participants who had lower motivation scores for either the extrinsic or intrinsic category. Additionally, participants who had high extrinsic and high intrinsic motivation significantly outperformed those who had low extrinsic and low intrinsic motivation. 
Considering the general academic success, Kaufman, Agars, and Lopez-Wagner (2008) investigated whether intrinsic and extrinsic motivation separately predicted students' performance. A significant positive relationship between intrinsic motivation and student performance was found, and there was a negative relationship between extrinsic motivation and student performance (Kaufman et al., 2008). Watson, McSorely, Foxcraft, and Watson (2004) studied the effects of both intrinsic and extrinsic motivation on a specific college final course grade. They found that higher levels of both motivation orientation variables positively correlated with higher course grades (Watson et al., 2004). Garcia (1993) found both intrinsic and extrinsic motivation positively predicted final course grades in organic chemistry. In contrast, Yu (1999) found that intrinsic motivation negatively predicted course performance in college chemistry. Glynn, Taasoobshirazi, and Brickman (2007) investigated the relationship between overall motivation to learn science and science performance. They reported that students found science courses relevant to their careers; both their motivation and science performance levels were higher. In another study, Glynn, Taasoobshirazi, and Brickman (2009) found that when college students reported lower motivation in science courses their performance was lower as well. However, students can be simultaneously intrinsically and extrinsically motivated (Kaufmann et al., 2008; Lin, McKeachie, \& Kim, 2002; Watson et al., 2004).

In spite of the unprecedented impact of Computer-Assisted Instruction (CAI) on science education in advanced countries, it has not made much headway in Nigeria. Little is known about the use of computer-assisted instructional package in the Nigerian educational system particularly the use of simulation and tutorial modes. In addition, very few empirical studies exist in Nigeria regarding the use of CAI as a motivator to chemistry learning. Therefore, much remain to be empirically studied on the effect of CAI in chemistry education in Nigeria.

\section{Research Questions}

The study is guided by the following research questions:

1. What are the differences in the achievement of students taught chemistry using computer simulation instructional package, computer tutorial instructional package and conventional teaching method?

2. Is there any difference in the mean achievement scores of male and female students exposed to Computer Simulation Instructional Package?

3. Is there any difference in the mean achievement scores of male and female students exposed to Computer Tutorial Instructional Package?

4. What are the differences in the intrinsic motivation of students taught chemistry using Computer Simulation Instructional Package, Computer Tutorial Instructional Package and Conventional Teaching Method?

5. What are the differences in the extrinsic motivation of students taught chemistry using Computer Simulation Instructional Package, Computer Tutorial Instructional Package and Conventional Teaching Method? 


\section{Research Hypotheses}

The following null hypotheses were formulated and tested at the 0.05 level of significance:

1. There are no significant differences in the performance of students taught chemistry using computer simulation instructional package, computer tutorial instructional package and conventional teaching method.

2. There is no significant difference in the mean achievement scores of male and female students exposed to computer simulation instructional package.

3. There is no significant difference in the mean achievement scores of male and female students exposed to computer tutorial instructional package.

4. There are no significant differences in the intrinsic motivation of students taught chemistry using computer simulation instructional package, computer tutorial instructional package and conventional teaching method.

5. There are no significant differences in the extrinsic motivation of students taught chemistry using computer simulation instructional package, computer tutorial instructional package and conventional teaching method.

\section{Methodology}

\section{Study Design}

This study adopted the pretest-posttest experimental group design, one of the quantitative research methods. Three levels of independent variables (two experimental groups and a control) and two levels of gender (male and female). The Experimental Group I was taught two selected concepts of chemistry using computer simulation instructional package (CSIP), Experimental Group II was taught the same concept using computer tutorial instructional package (CTIP) whereas the Control Group received the conventional teaching method (CTM). Comparisons of the academic performance and motivation of the learners in chemistry were drawn by comparing the responses of the learners in the three groups.

\section{Population and Sample}

Multi-stage sampling techniques were adopted for the purpose of this study. First, a purposeful sampling procedure was adopted to obtain three secondary schools in Minna metropolis of Niger State, Nigeria. These schools were sampled based on facilities (laboratories and manpower), school type (public schools), and gender composition (co-educational schools). The three schools were randomly assigned to Experimental Group I (CSIP group), Experimental Group II (CTIP group) and Control Group (CTM group) respectively. Stratified sampling technique was used to select the $90 \mathrm{SSI}$ students. Each group had 30 students (15 male and 15 female). Finally, purposeful sampling was also used to select 5 students from each of the groups for the interview scheduled. 


\section{Research Instruments}

Data were collected by employing Chemistry Achievement Test (CAT), Chemistry Motivational Questionnaire (CMQ) and an interview guide as well as classroom observations. Both CAT and CMQ were administered by the first researcher as a pre-test and subsequently as a post-test. Questions in the post-test were the same like those used in the pre-tests; however, questions in the post-tests were numbered differently to avoid recognition. The pre-tests assessed the two experimental groups' and the control groups' prior knowledge of the chosen chemical concepts while the $\mathrm{CMQ}$ assessed their motivation toward chemistry learning. The post-tests assessed the learners' understanding and motivation of concepts after the instruction. An interview guide of open-ended questions was also used to collect detailed information from five selected learners in each group regarding the subject to determine their motivation towards chemistry. The classroom observations were also carried out in order to determine what the students were actually doing during the lessons.

\section{Chemistry Achievement Test (CAT)}

The Chemistry Achievement Test (CAT) consists of 50 multiple choice objective items with five options (A-E) adopted from past examinations of West African Examination Council (WAEC, May/June 2008 - 2012) and National Examination Council (NECO, June/July, 2008-2012). The content validity of CAT was established by matching the test items with the subject matter outlined in the Nigerian chemistry O-level teaching syllabus. The appropriateness of the options provided for each item was checked by four independent reviewers (subject teachers, test and measurement experts, University lecturers and secondary school teachers) and suggestions were incorporated in the final version which consisted of 50 questions. To establish reliability of CAT, the achievement test was piloted to 50 learners in another school within the same local government and a Cronbach Alpha 0.89 was obtained and this was considered to be acceptable.

\section{Chemistry Motivational Questionnaire (CMQ)}

Chemistry Motivational Questionnaire (CMQ) was adopted from Science Motivation Questionnaire by Glynn and Koballa (2006). Science Motivational Questionnaire (SMQ) has six motivational components, each component has five-item five point scale and their associated items included intrinsically motivated science learning, extrinsically motivated science learning, personal relevance of learning science, self-determination (responsibility) for learning science, self-efficacy (confidence) in learning science, and anxiety about science assessment. In this study, two components were chosen for measuring the intrinsic and extrinsic motivation of students toward chemistry. CMQ has ten-items which contain 5 -items for intrinsically motivated chemistry learning (items 1, 2, 3, 4, and 5), and 5-items for extrinsically motivated chemistry learning (items 6, 7, 8, 9, and 10). It consists of five point Likert type items (Never, coded as 1; Rarely, coded as 2; Sometimes, coded as 3; Usually, coded as 4, \& Always, coded as 5). 
Examples of items in intrinsically motivated chemistry learning component include; "I enjoy learning the chemistry"; "The chemistry I learn is more important to me than the grade I receive". Examples of items in extrinsically motivated chemistry learning components include; "I like to do better than the other students on the chemistry tests"; "I think about how my chemistry grade will affect my overall grade point average". Glynn, Taasoobshirazi, and Brickman (2007) had earlier pilot studied the 30-item Science Motivation Questionnaire with science and non-science majors students and 0.93 reliability coefficient was obtained using Cronbach Alpha reliability coefficient. These items were found to be reliable and valid. SMQ items which had been previously used for college students, they are therefore considered to be suitable for Senior Secondary One science students in Nigeria.

\section{Interview Schedule}

In order to get deeper understanding of the students' intrinsic and extrinsic motivation, five students were interviewed from each group. The students were asked questions such as "Based on the two topics you have learned so far (1) did you enjoy learning the chemistry? (2) do you think you have accomplished a lot by learning chemistry this way? (3) do you think that using computer simulations could help you to understand chemistry better? (4) do you think you will do better than the other students on the tests?"

\section{Learning Environment}

The learning environment for this study comprised of Computer Simulation Package (CSP) and Computer Tutorial Package (CTP). The packages which were validated by team of experts consist of concepts of periodicity and chemical equations.

In Computer Simulation Package, computer presented information and displayed animation to the learner in each of the units. Information was presented in form of a frame, mastery of a frame led to the presentation of the next frame. In other words, students could only proceed to the next frame if they satisfactorily answered the questions in that frame. This approach used drill and practice and it allowed students to move at his/her own pace, get immediate feedback, and feel the movement of the objects among others.

In the Computer Tutorial Package, computer displayed information to the learner on each of the units with static pictures after which the students jot down the key concepts in their notebook. At the end of each unit, students assessed themselves with objective questions. Computer displayed the number of questions scored correctly and those wrongly answered. The correct answers were displayed against the wrong answers for students to compared and take corrections. Students moved to the next lesson if they satisfactorily answered the questions and obtained a score of $70 \%$. However, when a student failed more than three questions (30\%), the computer package gave a remedial lesson on that particular concept or questions then he/she moved to the next unit. 


\section{Research Procedure}

After obtaining permission from the three schools' administrators to conduct the study, the researcher installed both CSP packages on the desktop computer system of treatment groups. The objectives and the modalities of the experiments were specified and operational guide was produced before the commencement of the treatment. After this, the researcher administered both CAT and CMQ pre-tests to the sampled students. This helped to ascertain the equivalence of the students before the treatment. Treatment was followed immediately; the two experimental groups were taught periodicity and chemical equations using Computer Simulation Package (CSP) and Computer Tutorial Package (CTP) respectively over a period of four weeks.

By incorporating computer simulation packages into the teaching of periodicity and chemical equations, the researchers assume that simulations would impact on the learners' learning by developing the learners' ability to break down the complex and abstract structure of the periodic table and balancing of the chemical equations. It will also enable the learners to resolve any misconceptions they might have about the concepts and improve their conceptual understanding. On the hand, the control group was taught using traditional method where the teachers will just teach the learners and give them note to read on their own but no computer simulations were used for them. Thereafter CAT and CMQ were administered as post-tests to measure the achievement and motivation of the sampled students in each of the school.

\section{Data Analysis}

Both quantitative and qualitative data were collected for the purpose of this research. The quantitative data collected were analyzed using Statistical Package for Social Scientists (SPSS) version 18. The data were analyzed based on the stated hypotheses using both descriptive statistics (mean and standard deviation) and inferential statistics (t-test, one-way Analysis of Variance, and Scheffe's test) were used to analyze the data. The significance of the various statistical analyses was ascertained at 0.05 alpha levels.

Data obtained from the guided interviews and classroom observations were analyzed thematically using Braun and Clarke (2006) approach where texts were read and re-read to de-contextualize information from primary data. Information was grouped into similar, dissimilar components and later re-examined against the purpose of study in order to generate themes.

\section{Results}

Hypothesis One: There are no significant differences in the performance of students taught chemistry using computer simulation instructional package, computer tutorial instructional package and conventional teaching method. 
To determine whether there was a significant difference in the post-test mean scores of computer simulation instructional package (SSIP), computer tutorial instructional package (CTIP), and traditional teaching method (TTM), data were analyzed using the analysis of covariance (ANCOVA). Table 2 shows the result of the analysis.

Table 2. ANCOVA Post-test on CSIP, CTIP and TTM Groups

\begin{tabular}{lccccc}
\hline Source of Variation & $\begin{array}{c}\text { Type III Sum of } \\
\text { Square }\end{array}$ & df & $\begin{array}{c}\text { Mean } \\
\text { Square }\end{array}$ & $\mathrm{F}$ & $\mathrm{p}$ \\
\hline Corrected Model & 6185.129 & 3 & 2061.710 & 891.317 & 0.000 \\
Intercept & 9941.210 & 1 & 9941.210 & 4297.778 & 0.000 \\
Covariate & 2.306 & 1 & 2.306 & 0.997 & 0.321 \\
(Pre-test) & & & & & \\
Main Effect & 6122.436 & 2 & 3061.218 & 1323.424 & 0.000 \\
(Treatment) & 198.927 & 86 & 2.313 & & \\
Error & 502931.000 & 90 & & & \\
Total & 6384.056 & 89 & & & \\
Corrected Total & & & &
\end{tabular}

Table 2 reveals that an $F(2,86)=1323.424, p=0.000$ for the main effect (treatment) was significant, this indicates that the method of instruction produced a significant effect on the posttest achievement scores of students when covariate effect (pre-test) was controlled. The results indicate that the treatment, using CSIP, CTIP and TTM accounted for the difference in the post-test achievement scores of the students. Based on the established significant difference in the posttest achievement scores of the groups, Scheffe's test was used for post-hoc analysis. The results of this post-hoc analysis are as shown in Table 3.

Table 3. Scheffe's Post-hoc Analyses of the Groups Mean Scores

\begin{tabular}{ccccc}
\hline Groups & $\begin{array}{c}\text { Mean } \\
\text { Scores }\end{array}$ & $\begin{array}{c}\text { Group I } \\
\text { (CSIP) }\end{array}$ & Group II (CTIP) & Group III (TTM) \\
\hline Group I (CSIP) & 83.07 & & ${ }^{*} 0.000$ & ${ }^{*} 0.000$ \\
Group II (CTIP) & 76.60 & ${ }^{*} 0.000$ & & ${ }^{*} 0.000$ \\
Group III (TTM) & 63.17 & ${ }^{*} 0.000$ & ${ }^{*} 0.000$ & \\
\hline
\end{tabular}

* The mean difference is significant at the 0.05 level.

The result in Table 3 indicates that there was no significant difference in the mean scores of students exposed to CIP $(X=83.07)$ and those exposed to CTIP $(X=76.60)$. It also indicates significant difference in the mean scores of students exposed to CTIP $(X=76.60)$ and those exposed to TTM $(X=63.17)$. Significant difference was also established in the mean scores of students exposed to CSIP $(X=83.07)$ and those exposed to TTM $(X=63.17)$. Therefore, significant difference was established among the three groups in favor of CSIP. 
Hypothesis Two: There is no significant difference in the mean achievement scores of male and female students exposed to computer simulation instructional package.

To determine whether there was significant difference between male and female using computer simulation instructional package CSIP group, data were analyzed using the analysis of covariance (ANCOVA). Tables 4 show the result of the analysis.

Table 4. ANCOVA Result of Male and Female Students in Computer Simulation Instructional Package (CSIP) Group

\begin{tabular}{lccccc}
\hline Source of Variation & $\begin{array}{c}\text { Type III Sum of } \\
\text { Square }\end{array}$ & df & $\begin{array}{c}\text { Mean } \\
\text { Square }\end{array}$ & $\mathrm{F}$ & $\mathrm{p}$ \\
\hline Corrected Model & 13.792 & 2 & 6.896 & 1.454 & 0.251 \\
Intercept & 3384.030 & 1 & 3384.030 & 713.406 & 0.000 \\
Covariate & 2.992 & 1 & 2.992 & 0.631 & 0.434 \\
(Pre-test) & 13.784 & 1 & 13.784 & 2.906 & 0.100 \\
Main Effect & 128.075 & 27 & 4.744 & & \\
(Treatment) & 207144.00 & 30 & & & \\
Error & 141.867 & 29 & & & \\
Total & & & & \\
Corrected Total & & & & & \\
\hline
\end{tabular}

The analysis in Table 4 shows that the main effect of treatment group 1 (computer-assisted CSIP) on gender produced an $F(1,27)=2.906, p=0.100$. This result was not significant at the 0.05 alpha level. This indicates that there was no significant difference in the performance of male and female students taught physics using computer simulation instruction package (CSIP). Hypothesis two was therefore not rejected. This implies that male students' achievement did not differ significantly from that of their female counterparts when both were taught using computer simulation instructional package.

Hypothesis Three: There is no significant difference in the mean achievement scores of male and female students exposed to computer tutorial instructional package.

To determine whether there was significant difference between male and female using computer tutorial instructional package (CTIP), data were analyzed using the analysis of covariance (ANCOVA). Tables 5 show the result of the analysis.

Table 5 indicates that the main effect of treatment (group 2 - computer tutorial instructional package on gender produced an $F(1,27)=0.105, p=0.797$ which was not significant at 0.05 alpha level. This shows that there was no significant difference between the mean achievement scores of male and female students. Male students' scores did not differ significantly from their female counterparts when both were taught using computer tutorial instructional package. Therefore, hypothesis two was not rejected. 
CONTEMPORARY EDUCATIONAL TECHNOLOGY, 2016, 7(1), 25-46

Table 5. ANCOVA Result on Male and Female Students in Computer Tutorial Instructional Package

\begin{tabular}{lccccc}
\hline Source of Variation & $\begin{array}{c}\text { Type III Sum of } \\
\text { Square }\end{array}$ & df & $\begin{array}{c}\text { Mean } \\
\text { Square }\end{array}$ & $\mathrm{F}$ & $\mathrm{p}$ \\
\hline $\begin{array}{l}\text { Corrected Model } \\
\text { Intercept }\end{array}$ & 3.164 & 2 & 1.582 & 1.016 & 0.375 \\
Covariate & 2892.651 & 1 & 2892.651 & 1857.651 & 0.000 \\
$\begin{array}{l}\text { (Pre-test) } \\
\text { Main Effect }\end{array}$ & 3.031 & 1 & 3.031 & 1.947 & 0.174 \\
(Treatment) & 0.105 & 1 & 0.105 & 0.067 & 0.797 \\
Error & 42.036 & 27 & 1.557 & & \\
Total & 176072.000 & 30 & & & \\
Corrected Total & 45.200 & 29 & & & \\
\hline
\end{tabular}

Hypothesis Four: There are no significant differences in the intrinsic motivation of students taught chemistry using computer simulation instructional package, computer tutorial instructional package and conventional teaching method.

To determine whether there were significant difference among CSIP, CTIP and TTM groups based on their level of intrinsic motivation, data were analyzed using the analysis of covariance (ANCOVA). Tables 6 show the result of the analyses.

Table 6. ANCOVA Result of CSIP, CTIP and TTM Students' Intrinsic Motivation

\begin{tabular}{lccccc}
\hline Source of Variation & $\begin{array}{c}\text { Type III Sum of } \\
\text { Square }\end{array}$ & df & $\begin{array}{c}\text { Mean } \\
\text { Square }\end{array}$ & $\mathrm{F}$ & P-value \\
\hline Corrected Model & 18.396 & 3 & 6.132 & 42.112 & 0.000 \\
Intercept & 100.011 & 1 & 100.011 & 686.853 & 0.000 \\
Covariate & 0.091 & 1 & 0.091 & 0.622 & 0.433 \\
$\begin{array}{l}\text { (Pre-test) } \\
\text { Main Effect }\end{array}$ & 18.120 & 2 & 9.060 & 62.222 & 0.000 \\
(Treatment) & 12.522 & 86 & 0.146 & & \\
Error & 1305.634 & 90 & & & \\
Total & 30.918 & 89 & & & \\
Corrected Total & & & & & \\
\hline
\end{tabular}

The result of the analysis in Table 6 indicates that an $F(2,86)=62.222, p=0.000$ for the main effect was significant at 0.05 alpha level. This implies that there was significant difference in the mean value of the CSIP, CTIP and TTM students' intrinsic motivation. This signifies that the use of computer simulation instruction package (CSIP), computer tutorial instruction package (CTIP) and traditional teaching method (TTM) influenced students' intrinsic motivation when the mean value at the pre-test had been statistically controlled using ANCOVA.

Scheffe post-hoc test was conducted to determine the direction of difference among the three groups. The result of the analysis is shown in Table 7. 
CONTEMPORARY EDUCATIONAL TECHNOLOGY, 2016, 7(1), 25-46

Table 7. Scheffe's Post-hoc Analyses of the CSIP, CTIP and TTM Groups

\begin{tabular}{ccccc}
\hline Groups & $\begin{array}{c}\text { Mean } \\
\text { Scores }\end{array}$ & Group I (CSIP) & $\begin{array}{c}\text { Group II } \\
\text { (CTIP) }\end{array}$ & Group III (TTM) \\
\hline Group I (CSIP) & 4.192 & & 0.066 & ${ }^{*} 0.000$ \\
Group II (CTIP) & 3.959 & 0.066 & & $* 0.000$ \\
Group III (TTM) & 3.140 & $* 0.000$ & $* 0.000$ & \\
\hline
\end{tabular}

* The mean difference is significant at the 0.05 level.

Table 7 shows significant difference in the mean values of CSIP $(X=4.192)$ and CTIP $(X=3.959)$ in favor of CSIP group. It also indicates that significant difference between CTIP group $(X=3.959)$ and TTM group $(X=3.140)$ in favor of CTIP group. Significant difference was established between CSIP group $(X=4.192)$ and TTM group $(X=3.140)$ in favor of CSIP group. Therefore, the CSIP group had higher intrinsic motivation than CTIP group and TTM groups respectively. Therefore, hypothesis four was rejected.

Hypothesis Five: There are no significant differences in the extrinsic motivation of students taught chemistry using computer simulation instructional package, computer tutorial instructional package and conventional teaching method.

To determine the significant differences among CSIP, CTIP and TTM groups' extrinsic motivation, the results is shown in Table 8.

Table 8. ANCOVA Result of CSIP, CTIP and TTM Students Intrinsic Motivation

\begin{tabular}{lccccc}
\hline Source of Variation & $\begin{array}{c}\text { Type III Sum of } \\
\text { Square }\end{array}$ & df & $\begin{array}{c}\text { Mean } \\
\text { Square }\end{array}$ & $\mathrm{F}$ & $\mathrm{p}$ \\
\hline Corrected Model & 13.938 & 3 & 4.646 & 23.872 & 0.000 \\
Intercept & 104.321 & 1 & 104.321 & 536.025 & 0.000 \\
Covariate & 0.005 & 1 & 0.005 & 0.027 & 0.869 \\
(Pre-test) & & & & 33.981 & 0.000 \\
Main Effect & 13.227 & 2 & 6.613 & & \\
(Treatment) & 16.737 & 86 & 0.195 & & \\
Error & 1460.214 & 90 & & & \\
Total & 30.675 & 89 & & & \\
Corrected Total & & &
\end{tabular}

The result of the analysis in Table 8 indicates that an $F(2,86)=33.981, p=0.000$ for the main effect was significant at 0.05 alpha level. This implies that there was significant difference in the mean value of the CSIP, CTIP and TTM students' extrinsic motivation. This signifies that the use of computer simulation instruction package (CSIP), computer tutorial instruction package (CTIP) and 
traditional teaching method (TTM) influenced students' extrinsic motivation when the mean value at the pre-test had been statistically controlled using ANCOVA.

Scheffe post-hoc test was conducted to determine the direction of difference among the three groups. The result of the analysis is shown in Table 9.

Table 9. Scheffe's Post-hoc Analyses of the CSIP, CTIP and TTM Groups

\begin{tabular}{ccccc}
\hline Groups & $\begin{array}{c}\text { Mean } \\
\text { Scores }\end{array}$ & Group I (CSIP) & $\begin{array}{c}\text { Group II } \\
\text { (CTIP) }\end{array}$ & Group III (TTM) \\
\hline Group I (CSIP) & 4.439 & & 0.003 & $* 0.000$ \\
Group II (CTIP) & 4.037 & 0.003 & & $* 0.000$ \\
Group III (TTM) & 3.480 & $* 0.000$ & $* 0.000$ & \\
\hline
\end{tabular}

* The mean difference is significant at the 0.05 level.

Table 9 shows significant difference in the mean values of CSIP $(X=4.439)$ and CTIP $(X=4.037)$ in favor of CSIP group. It also indicates that significant difference between CTIP group $(X=4.037)$ and TTM group $(X=3.480)$ in favor of CTIP group. Significant difference was established between CSIP group $(X=4.439)$ and TTM group $(X=3.480)$ in favor of CSIP group.

Therefore, the CSIP group had higher extrinsic motivation than CTIP group and TTM groups respectively. Therefore, hypothesis four was rejected.

In addition to the achievement and motivational tests, which was used to assess the learners' knowledge and motivational strategy when learning periodic table and balancing of the chemical equations, an interview guide was conducted for 5 students in each of the groups. This enabled the researchers to have deeper understanding of the students' motivational strategy when learning chemistry. Students in the CSIP and the CTIP groups who were taught chemistry using computer simulation instructional package and computer tutorial instructional package respectively were asked about how they enjoyed their learning as against learning in their normal traditional method of learning.

Three themes; preference, engagement, and confidence were identified from both interview and classroom observation of the experimental groups and one or two quotations are presented on each of them below:

Preference: One of the questions asked to the students in the interview guide was that learners should tell us whether they enjoyed enjoy learning the chemistry based on the just completed lesson where they used computer simulation instructional package. The vast majority of the learners reported that they liked the concept of balancing the given equation on the screen by adding coefficients so that the equation is balanced correctly. For instance, one learner commented that: using computer simulation, I was able to count the number of molecules on right hand and that of left hand. If they are equal then I know the equation is balanced. 
Base on all the students' responses to the experience of learning with computer simulations, it can be said that they preferred trying out things on their own instead of the teacher telling them or writing the balanced equation for them as would be the case if computer simulations were not integrated in the teaching and learning process.

Engagement: The classroom observations of the students in the Experimental Group I and the students' response to our question on what they think about their accomplishment by learning chemistry using computer simulation provide confirmatory evidence of the students' engagement during learning processes. Of particular note is their use of the computer simulation to balance equation easily and with excitement. The researchers' classroom observation notes show that students in the Experimental Group I especially were engaged with the learning activity throughout the period of the study compared to the other two groups. Perhaps this is because, as one of the students we interviewed noted, the use computer simulation makes the activities seem more like what "real scientists do. As another student commented, "It's really fun. It's nicer than the traditional method."

Confidence: Learners were asked if and how a computer could make difficult concepts easy for them to understand. In their responses, most of the learners agreed that a computer could make difficult concepts simple and easier to understand. They also explained that the manner in which a computer presents concepts is fascinating and because of its multi-functionality it can combine sound and visual aspects. Learners explained that seeing the movement of molecules in form of moving pictures and text actually eliminate the abstractness of concepts and present a virtual reality, which makes complex concepts seem simple. They remarked that:

Computer simulations are wonderful and exciting because one can visibly see the pictures and the text on the screen at the same time.

In the case of the Control Group, only one theme was identified: both periodicity and balancing chemical equations were difficult. All learners indicated that periodicity and balancing chemical equations were difficult for them to understand. Finally, learners in the Control Group confessed that studying chemistry was boring to them and that there was no way in which it could be easily understood.

In sum, findings show that the use computer simulation can increase motivation and engagement in learning, especially their motivation towards exploring difficult concepts on their own.

\section{Discussion}

This study investigated the influence of computer-assisted instruction towards promoting intrinsic and extrinsic motivation as well as learners' achievements when learning chemistry. Since the learners' understanding of both periodic table and balancing of the chemical equation concepts was established from the pre-tests, which was administered to all the groups, any difference in the achievement and the motivational strategy should be accounted to the computer simulations and computer tutorial, which were only utilized in the two experimental groups. Results show that 
there was no statistically significant difference between the performance of the two experimental groups and control group in the pre-test (F-value $(1.066, p=0.349)$ (Table 2$)$, implying that the three groups were similar.

Therefore, results of hypothesis one which reveals that there was significant difference in the learning achievements of those taught chemistry concepts with computer simulation, computer tutorial and traditional method in favor of computer simulation and tutorial respectively.

This result agrees with the findings of Akpan and Andre (2000), Winberg and Headman (2007) and Saminathan (2012) who found computer simulation instructional strategies to be an effective teaching strategy than the traditional method of teaching chemistry. However, the findings disagree with earlier findings of Winn, Walker, Greene \& Mansell (2007) which reported that the use of computer simulations to be less effective than traditional instruction and hands-on laboratory approaches.

This result also agrees with the findings of Badmus (2007), Egunjobi (2004), Kara and Yesilyurt (2007), Yaakub and Finch (2001) which revealed the effectiveness of computer tutorial mode over the traditional method in classroom setting across different disciplines at secondary schools level both in Nigeria and outside Nigeria. However, it disagrees with the finding of Ramanchandram and Scottler (2003) which found no significant difference between the traditional method and tutorial mode on achievement.

The results of hypothesis two and three show that there is no gender effect on the achievement of male and female students taught chemistry concepts with computer simulation and tutorial modes. This finding is in agreement with the results of Adesoji and Babatunde (2005), Gambari (2004), Fagbemi, Gambari, Gbodi and Oyedum, (2012) who found that male and female students performed equally well in chemistry, biology, physics and social studies using Computer-based instructional packages.

The results of hypothesis four showed significant differences in the intrinsic motivation of students taught chemistry using computer simulation, tutorial and conventional traditional method in favor of simulation and tutorial respectively. This finding is in agreement with the results of Winn, Walker, Greene \& Mansell (2006) who reported that intrinsically motivated students are more likely to persist with challenging tasks and other positive classroom behaviors as well as performs better academically.

The results of hypothesis five showed significant differences in the extrinsic motivation of students taught chemistry using computer simulation, tutorial and conventional traditional method in favor of simulation and tutorial, respectively. This finding is in line with the results of Glynn, Taasoobshirazi, and Brickman (2009) who found that when college students reported lower motivation in science courses their performance was lower as well. Similarly, Moos (2010) found that participants who had high extrinsic and high intrinsic motivation significantly outperformed those who had low extrinsic and low intrinsic motivation. This finding positively correlated to the performance of students exposed to simulation and tutorial respectively. 
Responses of the learners to the interview questions as well as the classroom observations suggest how chemistry concepts could best be taught to the learners in order to simplify learning. In response, all the learners from the CSIP group indicated that chemistry should be taught using computer simulations in addition to computer tutorials. Overall learner assessments in the CSIP group suggested that lessons were very interesting, exciting and educative. This in a way could explain why, learners in the CSIP outperformed those in the CTIP and CTM groups on both achievement and motivational tests.

This study therefore shows that learners exposed to computer simulations performed best on chemistry achievement and motivational tests when compared to those taught without computer simulations, this therefore confirms the effectiveness of computer simulations. While the teachers may find it difficult to explain certain facts to the learners, computer simulations provide simplified explanations that can be easily followed by the learners. Based on the fact that learners find learning with computer simulation easier and interesting, learners in a way became highly motivated towards learning chemistry as a subject in the school.

In general, the results support the findings of Watson, McSorely, Foxcraft, and Watson (2004) who found that higher levels of both motivation orientation variables positively correlated with higher course grades. It is also in line with Garcia (1993) who found both intrinsic and extrinsic motivation positively predicted final course grades in organic chemistry.

\section{Conclusion}

The study investigated how intrinsic and extrinsic motivation could enhance achievement in Chemistry among the senior secondary school students using computer simulation instructional package and computer tutorial instructional package.

Computer simulation and computer tutorial were found to enhance both intrinsic and extrinsic motivation. Students exposed to computer simulation have higher extrinsic and intrinsic motivation than their counterparts in computer tutorial and conventional method, respectively.

Results show that computer simulation and computer tutorial were found to enhance learning achievement as well as intrinsic and extrinsic motivation. In addition gender has no effect on the achievement of male and female students taught chemistry concept with computer simulation and tutorial modes. Both male and female students performed equally well on the chemistry achievement test using computer simulation and tutorial modes, above the traditional method.

\section{Recommendations}

From the findings of this study, the following recommendations were offered:

1. Teachers should be ICT compliant in order to cope with current trends in pedagogical practices and institution needs to expand their network. Science teachers should be 
trained on the effective use of computer for instruction through seminars, workshops and conferences.

2. The use of computer simulation and tutorial instructional strategies should be used to bridge the academic gaps that might exist between male and female science students.

3. Students' are likely to perform better if they are intrinsically and extrinsically motivated. Therefore, the use of computer simulation and computer tutorial should be used to increase students' motivation and enhance their active participation.

4. Finally studies using subjects other than science to confirm or refute our findings on the use of computer simulation is highly recommended.

\section{References}

Achuonye, K. A. (2011). Using computer in science class: The interactive effect of gender. Journal of African Studies and Development, 3(7), 131-134.

Adegoke, B. A. (2011). Effect of multimedia instruction on senior secondary school students' achievement in Physics. European Journal of Educational Studies, 3(3), 537-541.

Adesoji, F. A. \& Babatunde, A. G. (2005). Expressive teaching behaviour: Bridging the gender gulf in secondary school chemistry achievement. International Journal of African \& African American Studies, 4(1), 54-61.

Akpan, J. P. \& Andre, T. (2000). Using a computer simulation before dissection to help students learn anatomy. Journal of Computers in Mathematics and Science Teaching, 19(3), 297-313.

Akram, M., Athar, H. M., \& Ali, M. (2011). The influence of computer assisted instruction (CAI) in chemistry on the students' achievement at higher secondary level. Journal of Social Sciences and Education, 1(4), 426-435.

Anagbogu, M. A. \& Ezeliora, B. (2007). Sex differences and scientific performance. Women Journal of Science and Technology, 4(1), 10-20.

Arwood, L. (2004). Teaching cell biology to non-science majors through forensics, or how to design a killer course. Cell Biology Education, 3(2), 131-138.

Badmus, A. M. (2007). Effect of practical demonstration method (PDM) and computer tutorial mode (CTM) on students' achievement and attitudes in some selected skills in technical education (Unpublished master's thesis). University of Ibadan, Nigeria.

Braun, V. \& Clarke, V. (2006). Using thematic analysis in psychology. Qual Res Psychol, 3(2),77-101.

Britner, S. L. \& Pajares, P. (2006). Sources of science self-efficacy beliefs of middle school students. Journal of Research in Science Teaching, 43(5), 485-499.

Burns, C. \& Myhill, D. (2004). Interactive or inactive? A consideration of the nature of interaction in whole class teaching. Cambridge Journal of Education, 34(1), 35-49.

Cavallo, A. M. L., Potter, W. H., \& Rozman, M. (2004). Gender differences in learning constructs, shifts in learning constructs, and their relationship to course achievement in a structured 
inquiry, yearlong college physics course for life science majors. School Science and Mathematics, 104(6), 288-300.

Covington, M. V. (2000). Goal theory, motivation and school achievement: An integrative review. Annual Review of Psychology, 51(2), 171-200.

Doering, A. \& Veletsianos, G. (2009). Teaching with Instructional Software. In M. D. Roblyer \& A. Doering (Eds.), Integrating Educational Technology into Teaching (pp.73-108). Upper Saddle River, NJ: Pearson Education.

Efe, H. A. \& Efe, R. (2011). Evaluating the effect of computer simulations on secondary biology instruction: An application of Bloom's taxonomy. Scientific Research and Essays, 6(10), 21372146.

Egunjobi, A. O. (2004). The relative effectiveness of computer-assisted instructional modes on students learning outcomes in geography (Unpublished doctoral thesis). University of Ibadan, Nigeria.

Emeke, E. A. \& Adegoke, B. A. (2001). The interaction effect of test response mode, students' numerical ability and gender on cognitive achievement in senior secondary school physics. Retrieved on 20 August 2013 from http://www.findarticles.com/p/articles/m993765/is_200611/.../pg2

Fagbemi, P. O., Gambari, A. I., Oyedum, N. A., \& Gbodi, E. B. (2011). Effects of computer-assisted instructional package on social studies achievement among senior primary school pupils in Niger State, Nigeria. Journal of Science, Technology, Mathematics and Education, 7(2), 204 214.

Federal Republic of Nigeria (FRN) (2009). National policy on education. Abuja: NERDC.

Gambari, A. I. (2004). Effects of computer-assisted instruction package on the performance of senior secondary students in physics in Minna (Unpublished master's thesis). Federal University of Technology, Minna, Nigeria.

Gambari, A. I., Falode, O. C., Fagbemi, P. O., \& Idris, B. (2013). Efficacy of virtual laboratory strategy on the achievement of secondary school students in Nigeria. Research in Curriculum Studies (RICs), 9(1), 9-20.

Gambari, A. I., Yaki, A. A., Gana, E. S., \& Ughovwa, Q. E. (2014). Improving secondary school students' achievement and retention in biology through video-based multimedia instruction. InSight: A Journal of Scholarly Teaching, 9, 78-91.

Garcia, T. (1993). Women and minorities in science: Motivational and cognitive correlates of achievement. Paper presented at the Annual Meeting of the American Educational Research Association. Atlanta, GA.

Glynn, S. M. \& Koballa, T. R. (2006). Motivation to learn in college science. In J.J. Mintzes \& W. H. Leonard (Eds.), Handbook of college science teaching (pp. 25-32). Arlington, VA: National Science Teachers Association Press.

Glynn, S. M., Taasoobshirazi, G., \& Brickman, P. (2007). Non-science majors learning science: A theoretical model of motivation. Journal of Research in Science Teaching, 44(8), 1088-1107. 
Glynn, S. M., Taasoobshirazi, G., \& Brickman, P. (2009). Science motivation questionnaire: Construct validation with non-science majors. Journal of Research in Science Teaching, 46(2), 127-146.

James, T. (2001). Effect of combining reflective writing with concept mapping and lecture method on pre-service N. C. E teacher's attitude and achievement in biology (Unpublished doctoral thesis). Ahmadu Bello University, Zaria.

Jegede, S. A. (2007). Student's anxiety towards the learning of chemistry in some Nigerian secondary schools. Educational Research and Review, 2(7), 193-197.

Kara, Y. \& Yesilyurt, S. (2007). Assessing the effects of tutorial and edutainment software programs on students' achievements, misconceptions and attitudes towards biology. Asia-Pacific Forum on Learning and Teaching, 8(2), 1-22.

Kaufman, J., Agars, M., Lopez, M., \& Wagner, M. (2008). Examining creativity in Turkey high ability studies. Journal of California State University, 18(2), 235-246.

Lin, Y. G., McKeachie, W. J., \& Kim, Y. C. (2002). College student intrinsic and/or extrinsic motivation and learning. Learning and Individual Differences, 13(1), 251-258.

Michael, K. Y. (2001). The effect of a computer simulation activity versus a hands-on activity on product creativity in technology education. Journal of Technology Education, 13(1), 31-43.

Moos, D. C. (2010). Nonlinear technology: Changing the conception of extrinsic motivation? Computers \& Education, 55(4), 1640-1650.

Olorukooba, S. B. (2007). Science, technology and mathematics (STM) education is for all students: Promoting effective teaching of STM subjects in our schools through teacher preparation. Proceedings of the $50^{\text {th }}$ Anniversary Conference of Science Teachers Association of Nigeria. (pp.3-6).

Rieber, L. P. (1990). Using computer animated graphics with science instruction with children. Journal of Educational Psychology, 82(1), 135-140.

Ryan, R. M. \& Deci, E. L. (2000). Intrinsic and extrinsic motivations: Classic definitions and new directions. Contemporary Educational Psychology, 25(1), 54-67.

Saminathan, B. (2012). Effect of computer based instructional strategies in learning chemistry at higher secondary level. International Conference on Software and Computer Applications (ICSCA 2012). IPCSIT Vol. 41. Singapore: IACSIT Press.

Trey, L. \& Khan, S. (2008). How science students can learn about unobservable phenomena using computer based analogies. Computers \& Education, 51(2), 519-529.

Tuysuz, C. (2010). The effect of the virtual laboratory on students' achievement and attitude in chemistry. International Online Journal of Educational Sciences, 2(1), 37-53.

WAEC (2012, May/June). Chief examiner's report. Lagos: Research and Statistics Unit, WAEC.

Walker, C. O., Greene, B. A., \& Mansell, R. A. (2006). Identification with academics, intrinsic / extrinsic motivation, and self-efficacy as predictors of cognitive engagement. Learning and Individual Differences, 16(1), 1-12. 
Wasagu, M. A. \& Muhammad, R. (2007). Female education in science, technology and mathematics and sustainable development in the new millennium. 50th Annual Conference Proceeding of STAN (pp.86-88).

Watson, M., McSorley, M., Foxcroft, C. \& Watson, A. (2004). Exploring the motivation and learning strategies of first year university learners. Tertiary Education and Management, 10(3), 193 207.

West African Examination Council (WAEC) (2003-2012). Examiners report in science subjects. Lagos: WAEC.

Winberg, T. M. \& Headman, L. (2007). Student attitudes toward learning, level of pre-knowledge and instruction type in a computer - simulation: Effects on flow experiences and perceived learning outcomes. Springer Sci. Bus. Media BV., 36, 269-287.

Yaakub, M. \& Finch, C. (2001). Effectiveness of computer-assisted instruction in technical education: A meta- analysis. Occupational Education Forum/Workforce Education Forum (OEF/WEF), 28(2), 5-19.

Yu, S. L. (1999). Women's motivation and strategy use in college science classes. Journal of Staff, Program, \& Organization Development, 16(1), 93-101.

Yusuf, M. O. \& Afolabi, A. O. (2010). Effects of computer assisted instruction (CAI) on secondary school students' performance in biology. The Turkish Online Journal of Educational Technology, 9(1), 62-69.

Zeegers, P. (2001). Approaches to learning in science: A longitudinal study. British Journal of Educational Psychology, 71(1), 115-132.

Correspondence: Isiaka A. Gambari, Associate Professor of Educational Technology, Department of Science Education, Federal University of Technology, Minna, Nigeria 